\title{
Genotype-phenotype correlation in Japanese patients with familial Mediterranean fever: differences in genotype and clinical features between Japanese and Mediterranean populations
}

Dai Kishida', Akinori Nakamura ${ }^{1,2^{*}}$, Masahide Yazaki ${ }^{1,3^{*}}$, Ayako Tsuchiya-Suzuki ${ }^{1}$, Masayuki Matsuda ${ }^{1}$ and Shu-ichi Ikeda'

\begin{abstract}
Introduction: Familial Mediterranean fever (FMF) is a hereditary autoinflammatory disease characterized by recurrent self-limiting fever and serositis that mainly affects Mediterranean populations. Many patients with FMF have been reported in Japan due to increasing recognition of this condition and the availability of genetic analysis for the gene responsible, MEFV. The present study was performed to elucidate the clinical characteristics of Japanese FMF patients and to examine the precise genotype-phenotype correlation in a large cohort of Japanese FMF patients.

Methods: We analyzed the MEFV genotypes and clinical manifestations in 116 patients clinically diagnosed as having FMF and with at least one mutation.

Results: The most frequent mutation in Japanese patients was E148Q (40.2\%), followed by M694I (21.0\%), L110P (18.8\%), P369S (5.4\%), and R408Q (5.4\%). In contrast, common mutations seen in Mediterranean patients, such as M694V, V726A, and M680l, were not detected in this population. The clinical features with M694I were associated with more severe clinical course compared to those seen with E148Q. P369S/R408Q showed variable phenotypes with regard to both clinical manifestations and severity. Patients with M694I showed a very favorable response to colchicine therapy, while those with P369S and R408Q did not.
\end{abstract}

Conclusions: Clinical features and efficacy of treatment in Japanese FMF patients vary widely according to the specific MEFV gene mutation, and therefore genetic analysis should be performed for diagnosis in cases of Japanese FMF.

\footnotetext{
*Correspondence: anakamu@shinshu-u.ac.jp; mayazaki@shinshu-u.ac.jp 'Department of Medicine (Neurology and Rheumatology), Shinshu University School of Medicine, 3-1-1 Asahi, Matsumoto 390-8621, Japan

${ }^{3}$ Department of Biological Sciences for Intractable Neurological Diseases,

Institute for Biomedical Sciences, Shinshu University, 3-1-1 Asahi, Matsumoto 390-8621, Japan

Full list of author information is available at the end of the article
}

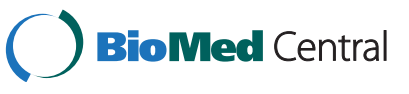

(c) 2014 Kishida et al.; licensee BioMed Central Ltd. This is an Open Access article distributed under the terms of the Creative Commons Attribution License (http://creativecommons.org/licenses/by/4.0), which permits unrestricted use, distribution, and reproduction in any medium, provided the original work is properly cited. The Creative Commons Public Domain Dedication waiver (http://creativecommons.org/publicdomain/zero/1.0/) applies to the data made available in this article, unless otherwise stated. 


\section{Introduction}

Familial Mediterranean fever (FMF) is an autosomal recessive disorder characterized by recurrent, self-limiting episodes of fever accompanied by peritonitis, pleuritis, synovitis, and erysipelas-like skin lesions [1]. The patients having severe FMF attacks sometimes develop lethal renal amyloid A (AA) amyloidosis. Typical FMF attacks usually last for approximately 3 days, and they vary in frequency from once a week to several times per year. Oral colchicine therapy is quite effective for preventing attacks and the development of reactive AA amyloidosis. The gene responsible, $M E F V$, maps to the short arm of chromosome 16 and encodes a protein of 781 amino acids called pyrin $[2,3]$. Though the mechanism of pyrin action is still debated, it is considered to be a negative regulator of inflammation [4].

FMF affects more than 100,000 people around the world, and is particularly prevalent in the Mediterranean basin, occurring most commonly in Turks, Arabs, Armenians, and Jews. Five mutations, M694V, V726A, M680I, M694I (in exon 10), and E148Q (in exon 2), account for $74 \%$ of FMF mutations [5]. However, increasing numbers of cases have been reported in different ethnic groups and countries [6]. In Japan, cases of FMF with $M E F V$ mutations were first reported in 2002 [7], and large numbers of FMF patients have been reported since even in Japan [8-13]. In addition, we described the clinical manifestations of FMF in 80 Japanese patients [14]. This study indicated that the severity of FMF is milder in Japanese than Mediterranean patients, with a lower frequency of AA amyloidosis, and the mutations are also different between Japanese and Mediterranean patients. However, FMF is still thought of as an uncommon disease in Japan, and the detailed clinical features associated with each type of $M E F V$ mutation in Japanese patients have not been elucidated. To date, a number of clinical diagnostic criteria have been used to make a diagnosis of FMF [15-18]. However, it is possible that some Japanese patients would not meet these diagnostic criteria as they are based on the symptoms seen in Mediterranean patients. Therefore, many patients may remain undiagnosed and a comprehensive diagnosis, including genetic analysis, may be necessary especially in countries outside the Mediterranean area, such as Japan. The present study was performed to examine the precise relationships between each type of $M E F V$ mutation and clinical manifestations in a large cohort of Japanese FMF patients. Moreover, we reconsidered the validity of the existing diagnostic criteria based on the genotypephenotype correlation seen in Japanese FMF.

\section{Materials and methods}

Patients

$M E F V$ mutation analyses were conducted on genomic DNA obtained from blood samples in patients with suspected FMF between September 2003 and December 2012. All patients provided informed consent prior to the genetic study for DNA testing of the $M E F V$ gene and publication of their individual details under anonymity. A total of 216 patients from various hospitals in Japan were referred to our department for $M E F V$ gene analyses. Clinical diagnosis of FMF was made according to the Tel-Hashomer criteria [15]. The major criteria are: 1) recurrent febrile episodes accompanied by peritonitis, synovitis, or pleuritis; 2) amyloidosis of the AA-type without predisposing disease; and 3) favorable response to colchicine treatment. Minor criteria were: 1) recurrent febrile episodes; 2) erysipelas-like erythema; and 3) FMF in a first-degree relative. Patients were divided into two groups based on the confidence of diagnosis: definitive FMF (two major or one major and two minor) and probable FMF (one major and one minor). A definitive or probable diagnosis could not be made in some cases despite recurrent febrile or painful episodes. To examine the genotypephenotype correlations of Japanese FMF patients, we included a third group called suspected FMF (one major or one minor), as described previously [19]. In 216 patients, 76 were clinically evaluated by FMF experts in our hospital. Other 140 patients were evaluated by physician contributors throughout Japan using our original clinical survey sheet for FMF. Based on the clinical information, we have carefully assessed and determined the groups (definitive, probable, and suspected) in each patient. All the genetic analyses were conducted only in our hospital. Of the 216 patients, 147 carried certain $M E F V$ mutation (s). Among these, 14 subjects were excluded on the basis of being asymptomatic family members of FMF patients. Moreover 17 patients were excluded due to the presence of different diseases: Behçet's disease $(n=5)$, inflammatory bowel disease ( $\mathrm{n}=2$ ), and sarcoidosis, mixed connectivetissue disease, adult-onset Still's disease, granulomatosis with polyangiitis, pseudogout, malignant lymphoma, infectious spondylitis, intercostal neuralgia, mental disorder, and temperature instability $(\mathrm{n}=1)$ (Additional file 1$)$. Consequently, we studied the clinical pictures and types of $M E F V$ mutations of the remaining 116 patients. Among them, 39 patients who were diagnosed at our University and presented in our previous report [14] were included in this analysis. On the other hand, 69 patients had no mutation in the $M E F V$ gene. Of 69 patients, 4 patients were definitive, 1 was probable, 39 were suspected, and 25 were not eligible according to the Tel-Hashomer criteria. This study was carried out in accordance with Institutional Review Board approval (No. 314) in the Shinshu University School of Medicine, Nagano, Japan.

\section{DNA testing of the MEFV gene}

DNA analysis of the $M E F V$ gene was performed in all 216 patients with suspected FMF. The five hotspot 
regions (exons 1, 2, 3, 5, and 10) for $M E F V$ mutations were analyzed by PCR [20]. Exon 2 was amplified in two overlapping PCR fragments, designated as exon $2 \mathrm{a}$ and exon $2 \mathrm{~b}$. Amplified PCR products were analyzed by direct sequencing (DNA Analyzer 3730xl; Applied Biosystems, Foster City, CA, USA). Primers for PCR and sequence analysis were as follows: Exon 1: 5'-TCC TAC CAG AAG CCA GAC AG-3'; Exon 1R: 5'-TTC CTG AAC TAA AGT CAT CT-3'; Exon 2aF: 5'-GCA TCT GGT TGT CCT TCC AGA ATA TTC C-3'; Exon 2aR: 5'-CTT TCC CGA GGG CAG GTA CA-3'; Exon 2bF: 5'-CAG GCC GAG GTC CGG CTG CG-3'; Exon 2bR: 5'-CTT TCT CTG CAG CCG ATA TAA AGT AGG-3'; Exon 3F: 5'GAA CTC GCA CAT CTC AGG C-3'; Exon 3R: 5'-AAG GCC CAG TGT GTC CAA GTG C-3'; Exon 5F: $5^{\prime}$-TAT CGC CTC CTG CTC TGG AAT C-3'; Exon 5R: $5^{\prime}$-CAC TGT GGG TCA CCA AGA CCA AG-3'; Exon 10F: 5'CCG CAA AGA TTT GAC AGC TG-3'; Exon 10R: 5'TGT TGG GCA TTC AGT CAG GC-3'.

\section{Statistical analysis}

We considered that to include more than 10 patients in each genotype was appropriate for statistical analysis. All data are expressed as the mean \pm SD for continuous variables. Multiple differences between groups were compared by one-way analysis of variance (ANOVA) followed by Tukey's post hoc test. Differences between categorical variables were analyzed using the chi-square test. In all analyses, $P<0.05$ was taken to indicate statistical significance. The statistical software, JSTAT [21], was used in the analyses.

\section{Results}

\section{MEFV gene mutations}

Among the 116 patients, 2 (1.7\%) were homozygous, 67 (57.8\%) were compound heterozygous, and 47 (40.5\%) were heterozygous for $M E F V$ mutations. Table 1 shows the distribution of $M E F V$ mutations in this cohort. Complex alleles were observed in 32 (27.6\%) patients. The detected mutations were E148Q (40.2\%), M694I (21.0\%), L110P (19.9\%), P369S (5.4\%), R408Q (5.4\%), R202Q (4.5\%), E84K (2.2\%), S503C (1.9\%), and G304R $(0.9 \%)$. Repartition of the mutations in Japanese patients and comparison with findings in the four classically affected ethnic groups, that is, Turks, Arabs, Armenians, and Jews, are shown in Figure 1. Although M694V, V726A, and M680I are common mutations in the above four ethnic groups [22-27] these mutations were not detected in our study population.

\section{Clinical features}

The male/female ratio in our study population was 51:65. The mean age at onset of symptoms was $23.7 \pm 13.6$ years, the mean frequency of attacks was $11.7 \pm 11.3$ per year, and the mean duration of attacks was $4.7 \pm 7.7$ days. The main clinical symptoms of the patients were as follows: high-grade fever with temperature $>38^{\circ} \mathrm{C}$ was observed in $83.6 \%$ of the patients, peritonitis in $62.1 \%$, pleuritis in $45.7 \%$, arthritis in $41.4 \%$, headache in $19.8 \%$, myalgia in $11.2 \%$, rash or erysipelas-like erythema in $6.8 \%$, and amyloidosis in $1.7 \%$ of patients. Among the 116 patients, $70(60.3 \%)$ were treated with colchicine and 64 (91.4\%)

Table 1 Distribution of MEFV mutations

\begin{tabular}{|c|c|c|c|c|c|}
\hline \multicolumn{2}{|l|}{ Homozygote } & \multicolumn{2}{|l|}{ Compound heterozygotes } & \multicolumn{2}{|l|}{ Heterozygote } \\
\hline Mutation & Number & Mutation & Number & Mutation & Number \\
\hline \multirow[t]{16}{*}{ M694I/M694I } & 2 & E148Q/M694I & 15 & E148Q/wild-type & 21 \\
\hline & & L110P/E148Q/M694I & 14 & M694l/wild-type & 13 \\
\hline & & L110P/E148Q & 13 & R202Q/wild-type & 8 \\
\hline & & L110P-E148Q/E148Q & 6 & E84K/wild-type & 3 \\
\hline & & P369S/R408Q & 4 & S503C/wild-type & 2 \\
\hline & & L110P/E148Q/P369S/R408Q & 4 & & \\
\hline & & E84K/L110P/E148Q & 2 & & \\
\hline & & M694I/S503C & 1 & & \\
\hline & & E148Q/S503C & 1 & & \\
\hline & & L110P-E148Q/L110P-E148Q & 1 & & \\
\hline & & L110P/E148Q/G304R & 1 & & \\
\hline & & E148Q/P369S/R408Q & 1 & & \\
\hline & & E148Q/E148Q-P369S-R408Q & 1 & & \\
\hline & & E148Q/R202Q/P369S/R408Q & 1 & & \\
\hline & & G304R/P369S/R408Q & 1 & & \\
\hline & & E148Q/R202Q & 1 & & \\
\hline Total & 2 & & 67 & & 47 \\
\hline
\end{tabular}




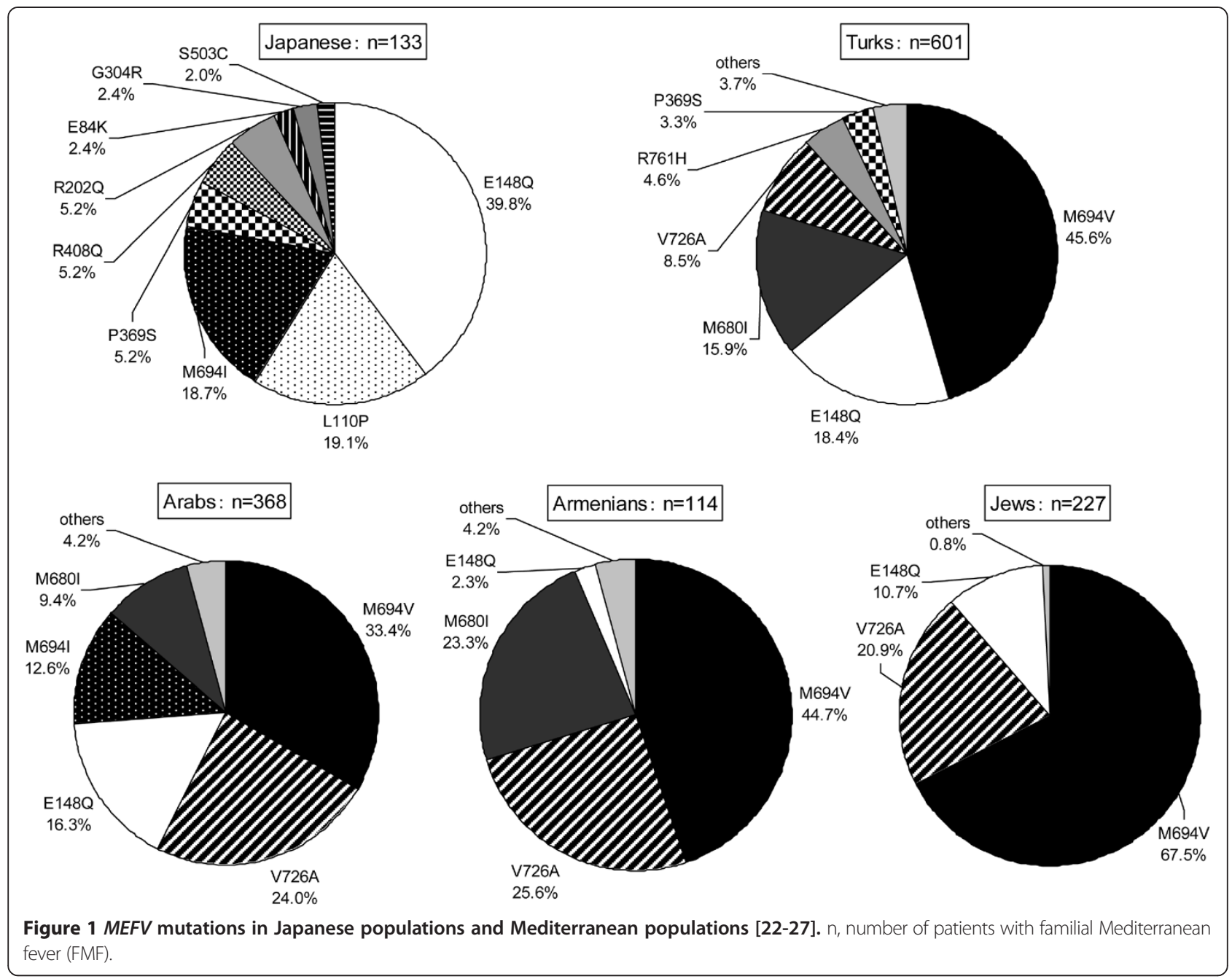

had complete response (asymptomatic) or good response (occasional attacks). The average dosage of colchicine was $0.8 \mathrm{mg} /$ day ( 0.25 to $2.0 \mathrm{mg} /$ day); $51.6 \%$ of the patients received $<0.5 \mathrm{mg} /$ day and $84.4 \%$ received $<1.0 \mathrm{mg} /$ day.

\section{Genotype-phenotype correlation}

The genotype-phenotype correlation of all patients was evaluated in more than three patients with same mutation (Table 2), and in one or two patients with the same mutation (Additional file 2). We next examined the features of attacks according to age at onset, frequency, and duration of attacks. In the majority of patients carrying the M694I mutation (E148Q/M694I, L110P/E148Q/ M694I, or M694I/wild-type), the age at onset was before 30 years, which was younger than for the other genotypes (Figure 2A). A portion of the patients who were not carrying M694I mutation had an age at onset $>30$ years and the disease developed in a few patients after age 40 years. The frequency of attacks in each genotype is shown in
Figure 2B. More than $40 \%$ of patients carrying E148Q/ wild-type experienced up to three attacks per year. Figure $2 \mathrm{C}$ shows the durations of attacks. Typically, the attacks in FMF patients resolve within 3 days [18], but the attacks lasted over 4 days in a number of patients. While attacks in all patients with M694I/wild-type improved within 3 days, $50.9 \%$ of patients not carrying this mutation had duration over 4 days.

We also analyzed the frequency of each symptom (fever, peritonitis, pleuritis, and arthritis). While high-grade fever (febrile episode; Figure 3A) was the most frequently observed symptom in each genotype group, $50 \%$ of the patients carrying L110P-E148Q/E148Q were afebrile or had low-grade fever. Peritonitis was observed in $92.3 \%$ of patients carrying M694I/wild-type, which was significantly higher than the patients carrying E148Q/wild-type (Figure 3B). Pleuritis was seen in over $60 \%$ of patients carrying the M694I mutation, but in under than 50\% of those without this mutation (Figure 3C). Arthritis was observed 
Table 2 Genotype-phenotype correlations in more than three patients with the same mutation

\begin{tabular}{|c|c|c|c|c|c|c|c|c|c|c|}
\hline & \multirow{2}{*}{$\begin{array}{l}\text { Patients, } \\
\text { number }\end{array}$} & \multicolumn{2}{|c|}{ Age at onset, years } & \multirow{2}{*}{$\begin{array}{l}\text { Frequency of attacks per year } \\
\text { Median (min, max) }\end{array}$} & \multirow{2}{*}{$\begin{array}{l}\text { Duration of } \\
\text { attacks (days) } \\
\text { Median (min, max) }\end{array}$} & \multirow{2}{*}{$\begin{array}{l}\text { Fever } \geq 38^{\circ} \mathrm{C} \\
\%\end{array}$} & \multirow{2}{*}{$\begin{array}{l}\text { Peritonitis } \\
\%\end{array}$} & \multirow{2}{*}{$\begin{array}{l}\text { Pleuritis } \\
\%\end{array}$} & \multirow{2}{*}{$\begin{array}{l}\text { Arthritis } \\
\%\end{array}$} & \multirow{2}{*}{$\begin{array}{l}\text { Efficacy of } \\
\text { colchicine } \\
\%\end{array}$} \\
\hline & & Mean $( \pm$ SD) & Range & & & & & & & \\
\hline E148Q/M694I & 15 & $18.8 \pm 7.8$ & 9 to 34 & $12(2.5,54)$ & $2.5(0.75,8.5)$ & 93.3 & 66.7 & 66.7 & 26.7 & $100(n=11)$ \\
\hline L110P/E148Q/M694I & 14 & $20.4 \pm 8.7$ & 13 to 46 & $12(2,30)$ & $3(2,7)$ & 85.7 & 85.7 & 78.6 & 50 & $100(n=12)$ \\
\hline M694I/wild-type & 13 & $20.2 \pm 11.4$ & 3 to 42 & $9(3,48)$ & $2.5(0.08,3)$ & 92.3 & 92.3 & 61.5 & 30.8 & $100(n=12)$ \\
\hline L110P/E148Q & 13 & $15.2 \pm 11.6$ & 2 to 48 & $5.5(1.5,18)$ & $3.3(1,17.5)$ & 84.6 & 69.2 & 0 & 38.5 & $83.3(n=6)$ \\
\hline L110P-E148Q/E148Q & 6 & $35.5 \pm 15.1$ & 18 to 65 & $12(3,12)$ & $5(0.75,8.5)$ & 50 & 66.7 & 50 & 16.7 & $100(n=3)$ \\
\hline E148Q/wild-type & 21 & $26.5 \pm 12.1$ & 7 to 61 & $4(1,24)$ & $2.5(1,75)$ & 81 & 52.4 & 42.3 & 47.6 & $81.8(n=11)$ \\
\hline P369S/R408Q & 4 & $35.5 \pm 16.7$ & 14 to 60 & $24(6,48)$ & $5.8(0.2,19)$ & 75 & 25 & 25 & 50 & $50(n=2)$ \\
\hline L110P/E148Q/ P369S/R408Q & 4 & $18.3 \pm 8.9$ & 6 to 31 & $18(5,24)$ & $4(2.5,7)$ & 100 & 25 & 50 & 25 & $50(n=2)$ \\
\hline R202Q/wild-type & 8 & $32.4 \pm 19.4$ & 11 to 68 & $15(4,48)$ & $5.8(1,14)$ & 87.5 & 50 & 25 & 75 & $33.3(n=3)$ \\
\hline E84K/wild-type & 3 & $20.7 \pm 6.2$ & 14 to 29 & $4(2,12)$ & $3(1.5,3.5)$ & 100 & 0 & 33.3 & 33.3 & $\mathrm{NE}$ \\
\hline
\end{tabular}

$\mathrm{SD}$, standard deviation, $\mathrm{NE}$, not examined 


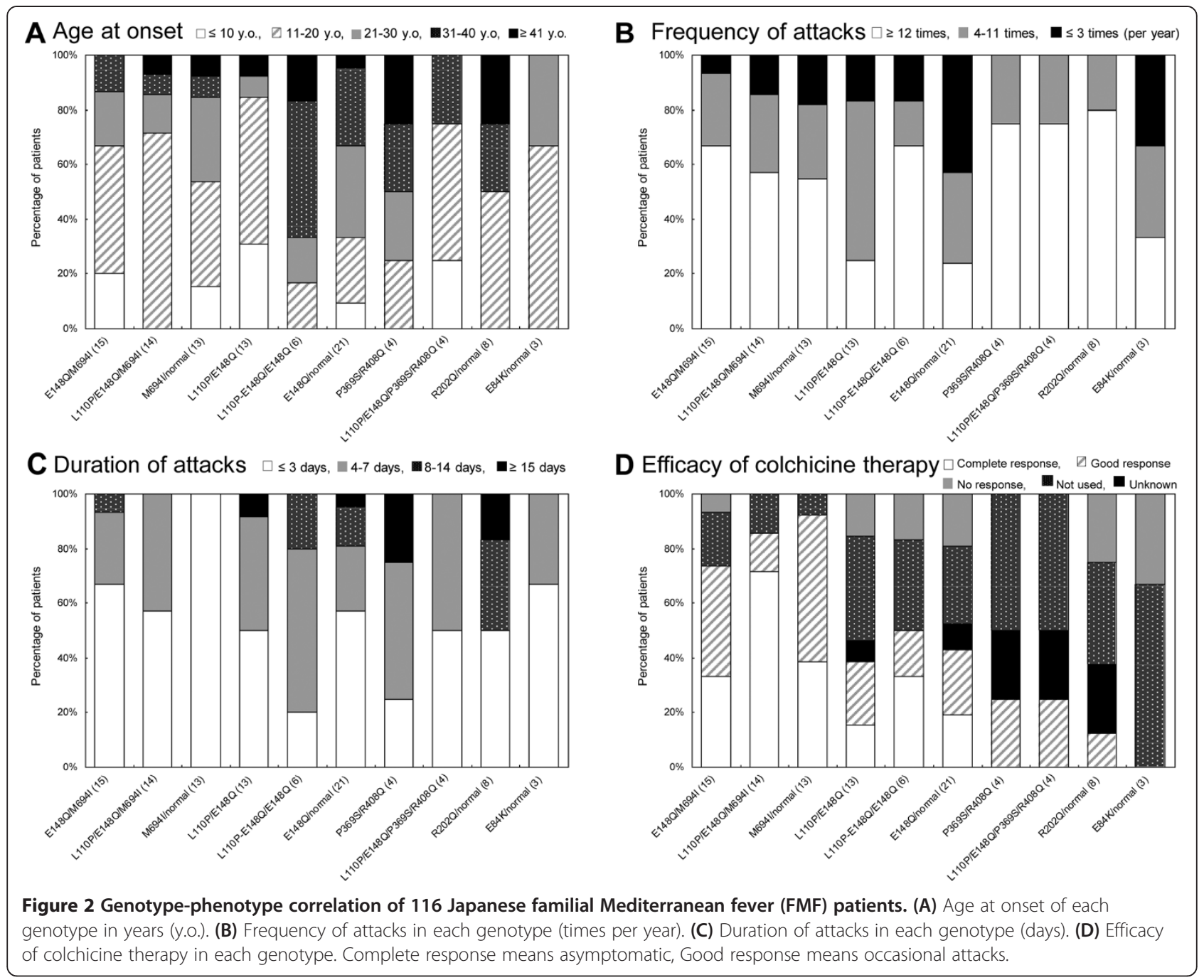

in $75 \%$ of patients with R202Q/wild-type (Figure 3D). This symptom was only seen in fewer than $50 \%$ of patients with other genotypes.

Next, we evaluated the efficacy of colchicine therapy in each genotype group (Table 2, Figure 2D). Patients carrying the M694I mutation had an efficacy rate of $100 \%$ (complete response or good response). Colchicine therapy had good efficacy in patients with the L110P and/or E148Q mutation (L110P/E148Q, L110P-E148Q/E148Q, and E148Q/wild-type), although its rate of use was approximately $50 \%$. In contrast, this treatment regimen had insufficient efficacy in patients with P369S/R408Q or R202Q/wild-type.

One patient with E148Q/M694I received a TNF- $\alpha$ receptor antagonist infliximab and low-dose methotrexate therapy because of colchicine intolerance for adverse events [28]. Further, some patients with the $M E F V$ gene mutations were refractory to colchicine and had atypical symptoms of FMF. To these patients, certain biological drugs such as TNF- $\alpha$ and IL-1 receptor antagonists might be effective.
Finally, we examined the diagnostic rate using the TelHashomer criteria in our patients with $M E F V$ mutations (Figure 4). According to these criteria, $88.1 \%$ of patients carrying the M694I mutation matched the definitive diagnosis, while this was true for only $64.4 \%$ of patients without M694I as a probable or suspected diagnosis. In particular, large numbers of patients in the P369S/ R408Q, R202Q/wild-type, and E84K/wild-type groups matched the criteria for a suspected diagnosis (Figure 4).

\section{Discussion}

In this study, we examined the frequency of $M E F V$ mutation, clinical manifestations, and the genotype-phenotype correlations in 116 Japanese patients with FMF. The clinical features of the Japanese patients were different from those seen in Mediterranean populations. Compared to Mediterranean patients, Japanese patients had late onset of symptoms, relatively low frequency of peritonitis, rarity of reactive AA amyloidosis, and low dosage of colchicine [14]. The results of the present study suggest 


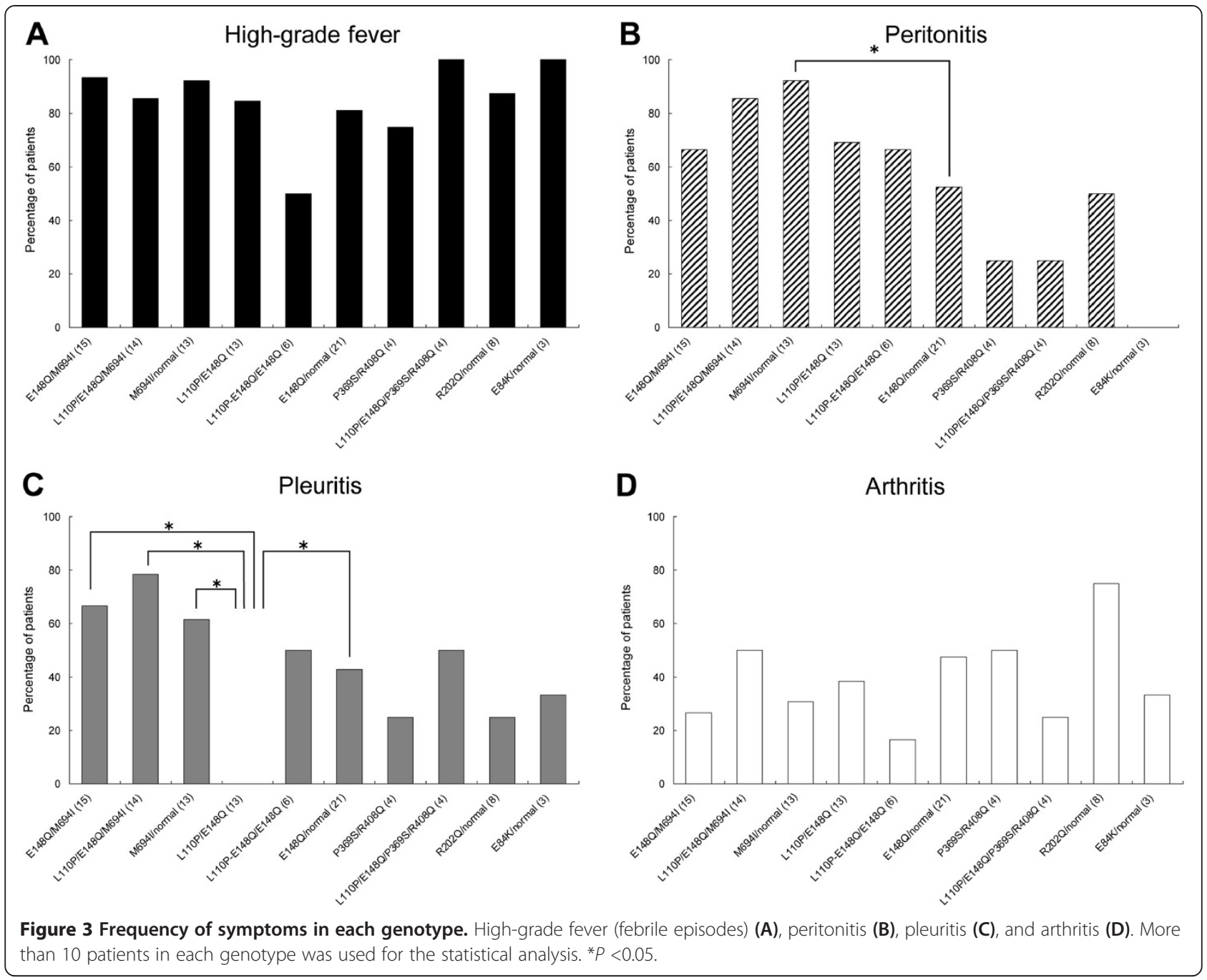

that the differences in mutations between Japanese and Mediterranean populations are associated with differences in genotype. Over 280 sequence variants in the $M E F V$ gene have been recorded in the Infevers database [29], the most common of which are M694V, M694I, V726A, M680I, and E148Q [5,19,30]. These five mutations account for approximately $90 \%$ of sequence variants in classically affected ethnic groups (Turks, Arabs, Armenians, and Jews) (Figure 1). However, only 61.2\% of Japanese FMF patients in the present study had E148Q and/or M694I, and none of our patients had M694V, V726A, or M680I. Especially, M694V, which is related to the most severe clinical course [19,30], has not been detected in Japanese patients. On the other hand, the largest number of Japanese patients with the E148Q mutation had a mild clinical course [5]. It has been suggested that FMF, along with Behçet's disease, may have been transmitted to Japan via travel along the Silk Road [6]. However, this hypothesis cannot explain the differences in mutation types between Japan and
Mediterranean regions and the low prevalence of FMF, compared to Behçet's disease, which is a common disease in Japan. As an island nation, Japan has a number of intrinsic disease features and Japanese patients have specific clinical presentations and mutation types.

As shown in Tables 1 and 2, the majority of Japanese FMF patients had some combination of M694I, E148Q, L110P, P369S/R408Q, and R202Q mutations. The presence of M694I in exon 10 is thought to be important for diagnosis and treatment. Patients with this mutation show a typical and severe clinical course, with early onset, high frequency and short duration of attacks, and high percentages of fever and serositis. However, their therapeutic response to colchicine is very good. Hence, identification of the M694I mutation is a useful diagnostic foundation for Japanese patients with suspected FMF.

E148Q has been considered to be a polymorphism because its allele frequency is high in healthy controls [31]. In Japan, it has been reported that allele frequency of E148Q, L110P, and M694I are 0.26, 0.039, and 0.0, 


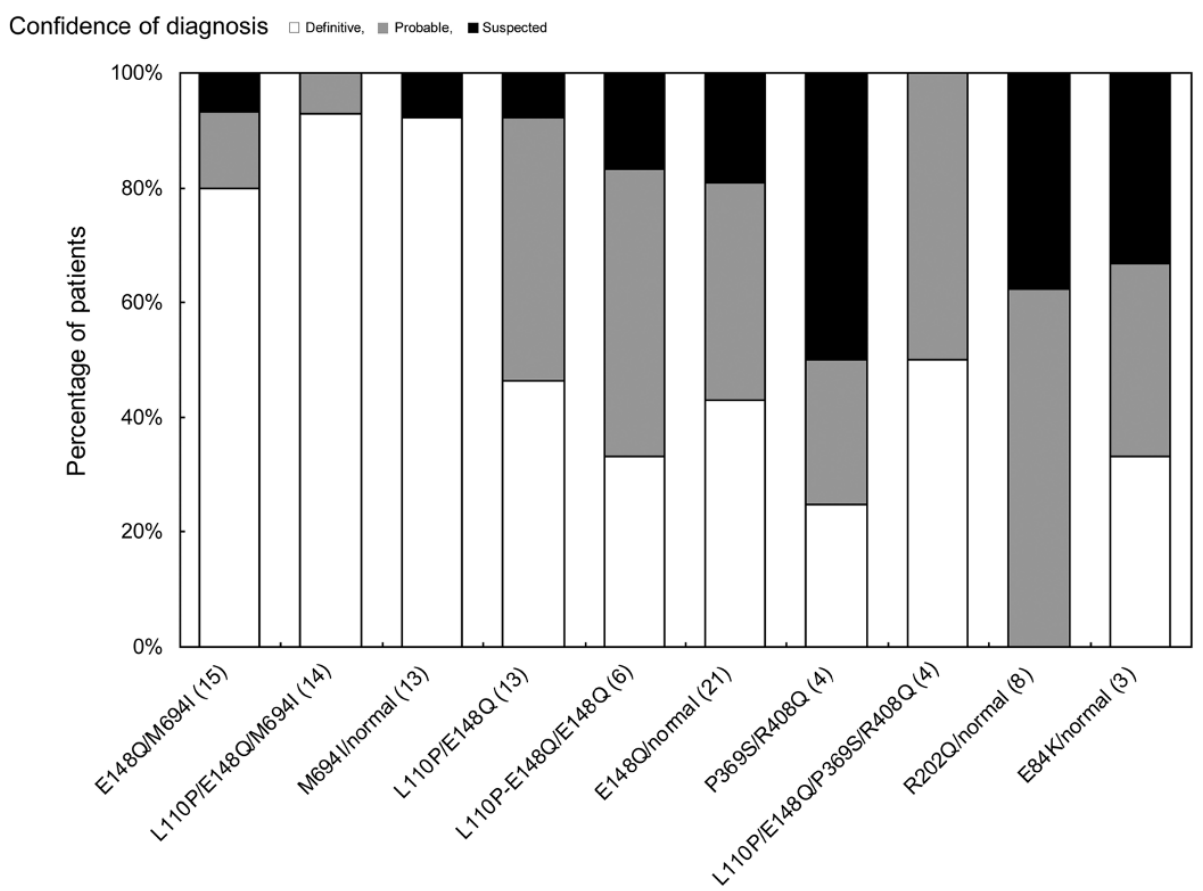

Figure 4 Confidence of diagnosis based on the Tel-Hashomer criteria in each genotype.

respectively [14]. Nevertheless, several studies have indicated that most homozygous or compound heterozygous patients associated with other $M E F V$ mutations are symptomatic and their clinical course is relatively mild $[5,32]$. In the present study, the clinical manifestations of patients with E148Q were later onset, lower frequency, and slightly longer duration of attacks, compared to patients with M694I. Moreover, some patients heterozygous only for E148Q presented with typical FMF manifestations. Generally, it is difficult to make a definite diagnosis in patients heterozygous for only E148Q. In such cases, a comprehensive diagnosis including not only the clinical course but also the efficacy of colchicine may be required.

The L110P mutation was always compound heterozygous with E148Q mutation, and there were no patients heterozygous for L110P alone. This mutation was identified commonly in our study and several cases of FMF with this mutation have been reported in Japan [33,34]. Although L110P may be a frequent mutation, especially in Japanese patients, there were no marked differences in the clinical picture between L110P/E148Q and E148Q alone.

In addition, it may be necessary to pay special attention to the diagnosis in patients with P369S/R408Q mutations in exon 3. P369S and R408Q are always identified in cis [35], as observed in our study. In the present study, 12 patients with P369S/R408Q (alone or with additional mutations) were identified, and their clinical features were characterized by a high frequency of attacks, variable phenotype, and incomplete efficacy of colchicine therapy. The mean frequency of attacks in these 12 patients was 22.5 times per year. Their clinical symptoms were highly variable: four were variable in frequency or duration of attacks, two experienced frequent abdominal attacks without high fever and elevation of serum $\mathrm{C}$-reactive protein (CRP) level, and other findings. Eight patients received colchicine therapy, but four had only a partial response, and the others showed no response. Ryan et al. report that patients with P369S/R408S mutations have clinical diversity, atypical clinical presentation, and relative lack of response to colchicine treatment [35]. This report is comparable to the phenotype in our patients with P369S/ R408S. Therefore, it will be necessary to establish other more effective therapies, including biological treatment, for such cases.

As indicated in the present study, there were differences in clinical characteristics between the various $M E F V$ mutations. As the majority of patients with M694I have typical FMF symptoms, identification of this mutation can lead to a definite diagnosis. When other mutations, such as E148Q and/or L110P, P369S/R408Q, R202Q, E84K, S503C, or G304R are identified, a comprehensive diagnosis including the efficacy of colchicine treatment may be required. Therefore, it is important to perform $M E F V$ gene analysis for diagnosis of patients with suspected FMF (recurrent febrile episodes and/or serositis, and exclude diagnosis of other diseases). After treatment with colchicine, it is important to examine the diagnostic validity. The possibility of FMF cannot be 
excluded even in the absence of detectable $M E F V$ mutations, but a careful colchicine trial is required.

\section{Conclusions}

The results of the present study indicated that the clinical characteristics and $M E F V$ genotypes of Japanese FMF patients are different from those seen in Mediterranean populations. Our clinical data established a spectrum of $M E F V$ mutations among Japanese patients. As clinical features and efficacy of treatment vary widely according to the mutation(s) present, comprehensive diagnosis including clinical data and genetic analysis is needed for Japanese FMF patients.

\section{Additional files}

\section{Additional file 1: The 17 patients excluded due to diagnosis of} other diseases.

Additional file 2: Genotype-phenotype correlations in selected patients.

\section{Abbreviations}

AA: amyloid A; FMF: familial Mediterranean fever; IL: interleukin; MEFV: Mediterranean fever; NE: not examined; PCR: polymerase chain reaction; TNF: tumor necrosis factor.

\section{Competing interests}

The authors declare that they have no competing interests.

\begin{abstract}
Authors' contributions
DK: conception and design, data collection and analysis, drafting of the manuscript and final approval of the manuscript. AN: conception and design, data collection and analysis, help in drafting the manuscript, critical revision and final approval of the manuscript. MY: conception and design, data collection and analysis, help in drafting the manuscript, critical revision and final approval of the manuscript. AT: data collection and analysis, critical revision and final approval of the manuscript. MM: data collection and analysis, critical revision and final approval of the manuscript. SI: data collection and analysis, critical revision and final approval of the manuscript. All authors read and approved the final manuscript
\end{abstract}

\section{Acknowledgements}

This study was supported by a grant-in-aid for research on intractable diseases from the Ministry of Health, Labour and Welfare of Japan and a grant-in-aid for Scientific Research (B) from the Ministry of Education, Culture, Sports, Sciences, and Technology of Japan to Akinori Nakamura (213001857) and Promotion Project of Education, Research, and Medical Care from Shinshu University Hospital to Dai Kishida. We would like to thank the following contributors for their effective and dedicated participation: Hiroyuki Yahikozawa, MD; Mihoko Yotsumoto, MD (Nagano Red Cross Hospital); Naoki Oomiya, MD; Osamu Watanabe, MD (Nagoya University Hospital); Yutaka Tsuchiya, MD; Shotaro Hanamura, MD; Yoshinori Sato, MD; Fumihiro Yamaguchi, MD (Showa University Fujigaoka Hospital); Naho Aikawa, MD (Tokyo Medical University Hospital); Shigeko Hara, MD; Tatsuya Suwabe, MD; Hideki Araoka, MD; Aya Imahuku, MD (Toranomon Hospital); Tomoko Tamaoki, MD (Hyogo Medical University Hospital); Yoshinobu Suzuki, MD (Shinonoi Suzuki Clinic); Kazuhiko Sekiguchi, MD (Sekiguchi Ladies Clinic); Keisuke Izumi, MD (Keio University Hospital); Shogo Itano, MD; Yoshihito Hayami, MD (Nagoya City University Hospital); Takafumi Tezuka, MD; Masaru Yamazoe, MD (Niigata City General Hospital); Tomoki Yonaha, MD (Japanese Red Cross Medical Center); Kumiko Ishida, MD (Kasugai Municipal Hospital); Ayumu Yamagami, MD (Fussa Hospital); Hiroe Sato, MD (Niigata Rheumatic Center); Tomohiko Sasaki, MD; Noriko Nara, MD (Yokohama City University Medical Center); Kiminori Hasegawa, MD; Takao Katsuragawa, MD; Ryutaro Morizono, MD (Kin-ikyo Chuo Hospital); Kenya Oguchi, MD (Chushin Matsumoto Hospital); Chisho Hoshino, MD (Saka General Hospital); Eri
Kawatani, MD; Yoshiaki Aomi, MD (Fukuoka University Chikushi Hospital); Yoko Wada, MD (Niigata University Hospital); Yuichiro Haba, MD (Juntendo University Hospital); Junichi Mise, MD; Takeshi Tanabe, MD (Jichi Medical University Hospital); Naohito Fujishima, MD (Akita University Hospital); Yuki Yasuda, MD (Tokyo Women's Medical University Medical Center East); Ryuichi Chiba, MD (lida Hospital), Yukihiro Ootaka, MD (Takasaki General Medical Center), Fumiaki Aoki, MD (Gunma University Hospital); Hiroshi Kasahara, MD (Suwa Red Cross Hospital); Takehisa Ogura, MD (Toho University Medical Center Ohashi Hospital); Michinori Yoshimi, MD (Kyoritsu General Hospital); Tomohisa Baba, MD (Kanagawa Cardiovascular and Respiratory Center); Ryosuke Hara, MD (Shinonoi General Hospital); Takamasa Tanaka, MD (Sakai City Hospital); Mito Daisuke, MD, Junwa Kunimatsu, MD (National Center for Global Health and Medicine); Tomomi, Abe, MD (Kawakita General Hospital); Kyoichi Nakajima, MD (East Saitama National Hospital); Kunihiro Yoshida, MD; Hiroshi Morita, MD; Wataru Ishii, MD; Akiyo Hineno, MD; Tomomi Kinoshita, MD; and Kenji Oka, MD (Shinshu University Hospital).

\section{Author details}

'Department of Medicine (Neurology and Rheumatology), Shinshu University School of Medicine, 3-1-1 Asahi, Matsumoto 390-8621, Japan. ${ }^{2}$ Intractable Disease Care Center, Shinshu University Hospital, 3-1-1 Asahi, Matsumoto 390-8621, Japan. ${ }^{3}$ Department of Biological Sciences for Intractable Neurological Diseases, Institute for Biomedical Sciences, Shinshu University, 3-1-1 Asahi, Matsumoto 390-8621, Japan.

Received: 15 January 2014 Accepted: 26 August 2014 Published online: 27 September 2014

\section{References}

1. Sohar E, Gafni J, Pras M, Heller H: Familial Mediterranean fever. A survey of 470 cases and review of the literature. Am J Med 1967, 43:227-253.

2. French FMF Consortium: A candidate gene for familial Mediterranean fever. Nat Genet 1997, 17:25-31.

3. The International FMF Consortium: Ancient missense mutations in a new member of the RoRet gene family are likely to cause familial Mediterranean fever. The International FMF Consortium. Cell 1997, 90:797-807.

4. Papin S, Cuenin S, Agostini L, Martinon F, Werner S, Beer HD, Grütter C, Grütter M, Tschopp J: The SPRY domain of Pyrin, mutated in familial Mediterranean fever patients, interacts with inflammasome components and inhibits prolL-1beta processing. Cell Death Differ 2007, 14:1457-1466.

5. Touitou I: The spectrum of familial Mediterranean fever (FMF) mutations. Eur J Hum Genet 2001, 9:473-483.

6. Ben-Chetrit E, Touitou I: Familial Mediterranean fever in the world. Arthritis Rheum 2009, 61:1447-1453.

7. Shinozaki K, Agematsu K, Yasui K, Nagumo H, Naitoh H, Naganuma K, Komiyama A: Familial Mediterranean fever in 2 Japanese families. J Rheumatol 2002, 29:1324-1325.

8. Migita K, Uehara R, Nakamura Y, Yasunami M, Tsuchiya-Suzuki A, Yazaki M, Nakamura A, Masumoto J, Yachie A, Furukawa $\mathrm{H}$, Ishibashi $\mathrm{H}$, Ida $\mathrm{H}$, Yamazaki K, Kawakami A, Agematsu K: Familial Mediterranean fever in Japan. Medicine (Baltimore) 2012, 91:337-343.

9. Inoue K, Torii K, Yoda A, Kadota K, Nakamichi S, Obata Y, Nishino T, Migita K, Kawakami A, Ozono Y: Familial Mediterranean fever with onset at 66 years of age. Intern Med 2012, 51:2649-2653.

10. Oshima K, Yamazaki K, Nakajima Y, Kobayashi A, Kato T, Ohara O, Agematsu K: A case of familial Mediterranean fever associated with compound heterozygosity for the pyrin variant L110P-E148Q/M680I in Japan. Mod Rheumatol 2010, 20:193-195.

11. Sugiura T, Kawaguchi Y, Fujikawa S, Hirano Y, Igarashi T, Kawamoto M, Takagi K, Hara M, Kamatani N: Familial Mediterranean fever in three Japanese patients, and a comparison of the frequency of MEFV gene mutations in Japanese and Mediterranean populations. Mod Rheumatol 2008, 18:57-59.

12. Nakamura A, Yazaki M, Tokuda T, Hattori T, Ikeda S: A Japanese patient with familial Mediterranean fever associated with compound heterozygosity for pyrin variant E148Q/M694I. Intern Med 2005, 44:261-265.

13. Matsuda M, Kishida D, Tsuchiya-Suzuki A, Fukushima K, Shimojima Y, Yazaki M, Ikeda S: Periodic peritonitis due to familial Mediterranean fever 
in a patient with systemic lupus erythematosus. Intern Med 2010, 49:2259-2262

14. Tsuchiya-Suzuki A, Yazaki M, Nakamura A, Yamazaki K, Agematsu K, Matsuda $M$, Ikeda S: Clinical and genetic features of familial Mediterranean fever in Japan. J Rheumatol 2009, 36:1671-1676.

15. Pras M: Familial Mediterranean fever: from the clinical syndrome to the cloning of the pyrin gene. Scand J Rheumatol 1998, 27:92-97.

16. Livneh A, Langevitz P, Zemer D, Zaks N, Kees S, Lidar T, Migdal A, Padeh S, Pras M: Criteria for the diagnosis of familial Mediterranean fever. Arthritis Rheum 1997, 40:1879-1885.

17. Armenian HK: Genetic and environmental factors in the aetiology of familial paroxysmal polyserositis. An analysis of 150 cases from Lebanon. Trop Geogr Med 1982, 34:183-187.

18. Yalçinkaya F, Ozen S, Ozçakar ZB, Aktay N, Cakar N, Düzova A, Kasapçopur O, Elhan AH, Doganay B, Ekim M, Kara N, Uncu N, Bakkaloglu A: A new set of criteria for the diagnosis of familial Mediterranean fever in childhood. Rheumatology 2009, 48:395-398.

19. Ozalkaya E, Mir S, Sozeri B, Berdeli A, Mutlubas F, Cura A: Familial Mediterranean fever gene mutation frequencies and genotype-phenotype correlations in the Aegean region of Turkey. Rheumatol Int 2011, 31:779-784.

20. Timmann C, Muntau B, Kuhne K, Gelhaus A, Horstmann RD: Two nove mutations $\mathrm{R} 653 \mathrm{H}$ and $\mathrm{E} 230 \mathrm{~K}$ in the Mediterranean fever gene associated with disease. Mutat Res 2001, 479:235-239.

21. [http://www8.ocn.ne.jp/ jstat/index.html].

22. Doğan HO, Koca Y, Erden G, Karaaslan Y, Bozat H: Evaluating MEFV mutation frequency in Turkish familial Mediterranean fever suspected patients and gender correlation: a retrospective study. Mol Biol Rep 2012, 39:6193-6196.

23. Majeed HA, El-Khateeb M, El-Shanti H, Rabaiha ZA, Tayeh M, Najib D: The spectrum of familial Mediterranean fever gene mutations in Arabs: report of a large series. Semin Arthritis Rheum 2005, 34:813-818.

24. Sabbagh AS, Ghasham M, Abdel Khalek R, Greije L, Shammaa DM, Zaatari GS, Mahfouz RA: MEFV gene mutations spectrum among Lebanese patients referred for Familial Mediterranean Fever work-up: experience of a major tertiary care center. Mol Biol Rep 2008, 35:447-451.

25. Cazeneuve C, Sarkisian T, Pêcheux C, Dervichian M, Nédelec B, Reinert P, Ayvazyan A, Kouyoumdjian JC, Ajrapetyan H, Delpech M, Goossens M, Dodé C, Grateau G, Amselem S: MEFV-Gene analysis in armenian patients with Familial Mediterranean fever: diagnostic value and unfavorable renal prognosis of the M694V homozygous genotype-genetic and therapeutic implications. Am J Hum Genet 1999, 65:88-97.

26. Dodé C, Pêcheux C, Cazeneuve C, Cattan D, Dervichian M, Goossens M, Delpech M, Amselem S, Grateau G: Mutations in the MEFV gene in a large series of patients with a clinical diagnosis of familial Mediterranean fever. Am J Med Genet 2000, 92:241-246.

27. Lidar M, Kedem R, Berkun Y, Langevitz P, Livneh A: Familial Mediterranean fever in Ashkenazi Jews: the mild end of the clinical spectrum. J Rheumatol 2010, 37:422-425.

28. Nakamura A, Matsuda M, Tazawa K, Shimojima Y, Ikeda S: Successful treatment with infliximab and low-dose methotrexate in a Japanese patient with familial Mediterranean fever. Intern Med 2007, 46:1247-1249.

29. INFEVERS: The registry of Familial Mediterranean fever (FMF) and Hereditary Autoinflammatory Disorders Mutations. [http://fmf.igh.cnrs.fr/ ISSAID/infevers/]

30. Jarjour RA: Familial Mediterranean fever in Syrian patients: MEFV gene mutations and genotype-phenotype correlation. Mol Biol Rep 2010, $37: 1-5$.

31. Tchernitchko D, Legendre M, Cazeneuve C, Delahaye A, Niel F, Amselem S: The E148Q MEFV allele is not implicated in the development of familial Mediterranean fever. Hum Mutat 2003, 22:339-340.

32. Topaloglu R, Ozaltin F, Yilmaz E, Ozen S, Balci B, Besbas N, Bakkaloglu A: $\mathrm{E} 148 \mathrm{Q}$ is a disease-causing MEFV mutation: a phenotypic evaluation in patients with familial Mediterranean fever. Ann Rheum Dis 2005, 64:750-752
33. Tomiyama N, Higashiuesato $Y$, Oda T, Baba E, Harada M, Azuma M Yamashita T, Uehara K, Miyazato A, Hatta K, Ohya Y, Iseki K, Jinno Y, Takishita S: MEFV mutation analysis of familial Mediterranean fever in Japan. Clin Exp Rheumatol 2008, 26:13-17.

34. Kim S, Ikusaka M, Mikasa G, Basugi A, Ohira Y, Nishizawa S, Itoga S, Sunaga M, Nomura F: Clinical study of 7 cases of familial Mediterranean fever with MEFV gene mutation. Intern Med 2007, 46:221-225.

35. Ryan JG, Masters SL, Booty MG, Habal N, Alexander JD, Barham BK, Remmers EF, Barron KS, Kastner DL, Aksentijevich I: Clinical features and functional significance of the P369S/R408Q variant in pyrin, the familial Mediterranean fever protein. Ann Rheum Dis 2010, 69:1383-1388.

doi:10.1186/s13075-014-0439-7

Cite this article as: Kishida et al:: Genotype-phenotype correlation in Japanese patients with familial Mediterranean fever: differences in genotype and clinical features between Japanese and Mediterranean populations. Arthritis Research \& Therapy 2014 16:439.

\section{Submit your next manuscript to BioMed Central and take full advantage of:}

- Convenient online submission

- Thorough peer review

- No space constraints or color figure charges

- Immediate publication on acceptance

- Inclusion in PubMed, CAS, Scopus and Google Scholar

- Research which is freely available for redistribution 